\title{
Butyrate mediates Caco-2 cell apoptosis via up-regulation of pro-apoptotic BAK and inducing caspase-3 mediated cleavage of poly-(ADP-ribose) polymerase (PARP)
}

Frank M. Ruemmele ${ }^{1}$, Serge Dionne', ljaz Qureshi', Dittakavi SR Sarma ${ }^{3}$, Emile Levy ${ }^{2}$ and Ernest G. Seidman ${ }^{\star, 1}$

1 Department of Pediatrics, Intestinal Immunology Laboratory, Ste. Justine Hospital, University of Montreal, Quebec, Canada

2 Department of Nutrition, Ste. Justine Hospital, University of Montreal, Quebec, Canada

${ }^{3}$ Department of Pathobiology and Laboratory Medicine, University of Toronto, Canada

* corresponding author: E.G. Seidman, Chief, Division of GastroenterologyNutrition, Ste. Justine Hospital, 3175 Cote Ste.-Catherine Rd., Montreal Quebec, H3T 1C5, Canada

tel: (1) 514345 4626; fax: (1) 514345 4999;

e-mail: seidmanernest@UMontreal.ca

Received 11.9.98; revised 15.2.99; accepted 20.5.99

Edited by D. Green

\begin{abstract}
Butyrate exerts potent anti-tumor effects by inhibiting cancer cell growth and inducing apoptosis. However, the molecular mechanisms mediating these effects remain largely unknown. Using the Caco-2 cell line, a well established model of colon cancer cells, our data show that butyrate induced apoptosis (maximum $79 \%$ ) is mediated via activation of the caspasecascade. A key event was the proteolytic activation of caspase-3, triggering degradation of poly-(ADP-ribose) polymerase (PARP). Inactivation of caspase-3 with the tetrapeptide ZDEVD-FMK completely inhibited the apoptotic response to butyrate. In parallel, butyrate potently upregulated the expression of the pro-apoptotic protein bak, without changing Caco-2 cell bcl-2 expression. Butyrateinduced Caco-2 cell apoptosis was completely blocked by the addition of cycloheximide, indicating the necessity of protein synthesis. However, when this inhibitor was added at a time point where bak expression was already enhanced $(12-16 h$ after butyrate stimulation), it failed to protect Caco-2 cells against apoptosis. Taken together, these data provide evidence that the molecular events involved in butyrate induced colon cancer cell apoptosis include the caspasecascade and the mitochondrial bcl-pathway.
\end{abstract}

Keywords: colon cancer; apoptosis; Caco-2 cells; butyrate; short chain fatty acid; caspase; bcl-2; bak

\section{Introduction}

Short chain fatty acids, particularly butyrate, are thought to play an important role in preventing the development of colon cancer. ${ }^{1-3}$ An inverse relationship between colon tumor mass and fecal butyrate levels was observed in rats, supporting this hypothesis. ${ }^{4}$ Various mechanisms have been proposed to explain how this particular short chain fatty acid inhibits tumorigenesis. Butyrate has been shown to inhibit cancer cell growth, leading to differentiation. ${ }^{5-7}$ Furthermore, butyrate is a potent inducer of apoptosis in cancer cells in vitro. ${ }^{8,9}$ Recently, Dolara et al ${ }^{10}$ provided evidence that oral administration of butyrate in form of an enteric-resistant slow-release pellet significantly increased colonocyte apoptosis rate in a rat model of colon cancer, indicating a potential anti-cancer effect in vivo.

Over the past few years, major advances have been made in our understanding of the molecular mechanisms that trigger apoptosis. The regulation of apoptotic cell death is often altered in transformed cells. The most common mutations in colon cancers cells are not surprisingly found among genes implicated in the regulation of apoptosis, including the p53 gene. ${ }^{11}$ An important pathway leading to apoptotic cell death is via the activation of the intracellular cascade of cysteine proteases, now referred to as caspases. $^{12}$ The recruitment of cytoplasmic death domains to activated membrane receptors, such as the p55 TNFreceptor or FAS, results in the activation of these caspases, which are synthesized as zymogens. This cascade is thought to represent a major regulatory step in the apoptotic pathway. One key endpoint in this cascade is activation of caspase-3, which cleaves several substrates such as the DNA-repair enzyme poly (ADP-ribose) polymerase (PARP) or DNA-fragmentation factor (DFF 45), leading to the typical $180 \mathrm{bp}-\mathrm{DNA}$ strand breaks observed in the course of apoptosis. Recently, Medina et $a l^{13}$ put forward evidence that butyrate induced apoptosis in cancer cells is triggered via activation of the caspase cascade.

In this study, the mechanisms of butyrate-induced apoptosis were studied using the Caco-2 colon cancer cell line. Butyrate induced apoptosis required the activation of caspase-3 and was completely abolished by specific caspase-3 inhibition. Rapid cleavage of PARP by caspase3 was observed in apoptotic Caco-2 cells in response to butyrate. Inhibition of protein synthesis by cycloheximide blocked the apoptotic effect of butyrate, indicating the necessity of protein-neosynthesis to execute apoptosis. Cycloheximide also inhibited the activation of caspase-3. Furthermore, butyrate induced upregulation of the proapoptotic protein bak in apoptotic Caco-2 cells was also suppressed by cycloheximide.

\section{Results}

\section{Effect of butyrate on Caco-2 cell proliferation}

Butyrate inhibited Caco-2 cell proliferation in a dosedependent manner, as shown in Figure 1. This effect was 
observed at concentrations as low as $0.1 \mathrm{mM}(89 \pm 3 \%$ versus control, $P<0.01$ ). Maximal inhibition by butyrate was noted at a dose of $10 \mathrm{mM}(62 \pm 8 \%$ versus control, $P<0.01)$.

\section{Effect of butyrate on Caco-2 cell apoptosis}

Under control conditions, near-confluent Caco-2 cell monolayers showed a spontaneous apoptosis rate of $9 \pm 3 \%$ after $24 \mathrm{~h}$, which gradually increased to $18 \pm 6 \%$ at $72 \mathrm{~h}$. Incubation with butyrate strongly induced Caco-2 cell apoptosis in a time- and dose-dependent manner, with an initial lag-phase at 14-16 h. A maximal apoptotic response of $79 \pm 12 \%$ was observed with $100 \mathrm{mM}$ butyrate after $24 \mathrm{~h}$ incubation (Figure 2a). Almost the same effect (76 $\pm 8 \%$ ) was seen with tenfold lower butyrate-concentrations when the incubation period was prolonged to $48 \mathrm{~h}$.

Butyrate-treated cells showed the typical morphological characteristics of apoptosis when analyzed by immunofluorescence. After staining with the DNA-dye HOECHST 3342, nuclear condensation and fragmentation were observed, as were the formation of apoptotic bodies (Figure 2b). Incubation of butyrate-treated Caco-2 cells with FITC-labeled annexin $\mathrm{V}$ revealed the presence of phosphatidyl serine on the external leaf of the plasma membrane (Figure 2c), an event characteristic of early apoptosis.

\section{Role of protein-synthesis in butyrate induced apoptosis}

Butyrate induced Caco-2 cell apoptosis was observed to be dependent on protein synthesis. Simultaneous incubation of Caco-2 cells with butyrate and the protein synthesis inhibitor cycloheximide $(100 \mu \mathrm{g} / \mathrm{ml})$ markedly suppressed the proapoptotic effect of the short chain fatty acid (Figure 3a). To

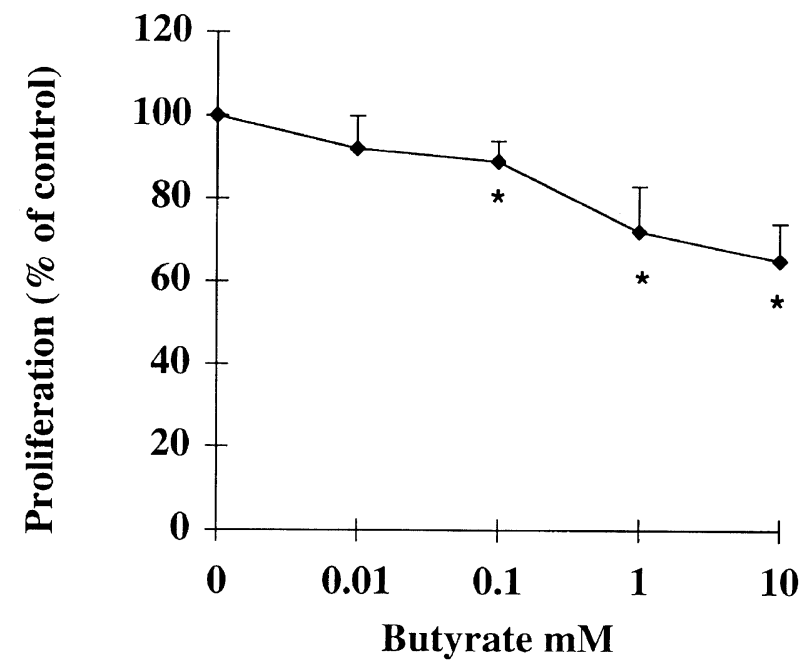

Figure 1 Effect of butyrate on Caco-2 cell proliferation. Caco-2 cells were cultured in the absence (control) or presence of butyrate at $0.01-10 \mathrm{mM}$ for $20 \mathrm{~h}$. Proliferation of the cells was measured by the incorporation of ${ }^{3} \mathrm{H}$-labeled thymidine, added $2 \mathrm{~h}$ prior to termination of the experiment. Basal proliferation without butyrate addition was set at $100 \%$. Results are expressed as mean \pm S.D. versus control for five experiments (in triplicate). ${ }^{\star} P<0.01$ further investigate the role of protein neosynthesis on butyrate induced Caco-2 cell apoptosis, cycloheximide was added at various time points after stimulation with butyrate. As shown in Figure 3b, butyrate-induced apoptosis was completely blocked if cycloheximide was added within $8 \mathrm{~h}$ of butyrate stimulation. Thereafter, the protective effect of cycloheximide was progressively less, with no significant protective effect if added $14 \mathrm{~h}$ or later after butyrate-stimulation.

\section{Activation of caspase-3 and subsequent degradation of PARP during butyrate-induced Caco-2 cell apoptosis}

Western blot analysis of butyrate treated Caco-2 cells revealed cleavage of the $32 \mathrm{kDa}$ pro-enzyme caspase-3 to its active $17 \mathrm{kDa}$ form (Figure $4 \mathrm{a})$. Butyrate $(5-100 \mathrm{mM})$ strongly activated this caspase, whereas lower doses failed to do so, consistent with the observation of a lack of apoptotic response at lower butyrate concentrations. In the presence of cycloheximide, no activation of caspase-3 was observed at all butyrate-doses tested (Figure 4b), indicating that protein synthesis was required upstream to activate the caspasecascade. In a second step, we assessed the degradation of the DNA-repair enzyme PARP, the known substrate of caspase-3. As shown in Figure 4c, minimal PARP-degradation was observed in unstimulated Caco-2 cells, indicating slight spontaneous apoptotic activity. Incubation with increasing doses of butyrate resulted in marked degradation of PARP, seen as a typical $89 \mathrm{kDa}$ band, which was almost complete at butyrate-concentrations of $100 \mu \mathrm{M}$.

\section{Inhibition of butyrate-induced Caco-2 cell apoptosis by ZDEVD-FMK}

The role of PARP degradation by caspase-3 in butyrateinduced Caco-2 cell apoptosis was further examined using the caspase-3 inhibitor zDEVD-FMK. This tetrapeptide corresponds to the sequence at the cleavage site of PARP. During its proteolysis, zDEVD-FMK binds irreversibly to caspase-3, thereby inactivating the enzyme. As shown in Figure 5, increasing doses of zDEVD-FMK suppressed the apoptotic effect of butyrate. Complete inhibition of butyrate $(10 \mathrm{mM})$-induced apoptosis was observed with zDEVD-FMK concentrations of $100 \mu \mathrm{M}$ and higher. However, when Caco-2 cells were treated with high butyrate doses $(50-100 \mathrm{mM})$ this inhibition of apoptosis was only partial $(69 \pm 6 \%)$. The caspase-inhibitor zVADFMK primarily inhibits caspases of the ICE-group, and at higher concentrations, also blocked caspases-3 and -6 . ZVAD-FMK also significantly reduced butyrate-induced Caco-2 cell apoptosis (Figure 5). No shift towards necrotic cell death in response to butyrate was observed when the caspase-cascade was completely blocked by high doses of zVAD-FMK (100 $\mu \mathrm{M}$ and higher).

\section{Butyrate-induced upregulation of bak expression during Caco-2 cell apoptosis}

Basal expression of the pro-apoptotic protein bak was low in Caco-2 cells. Expression of this protein was strongly 
A

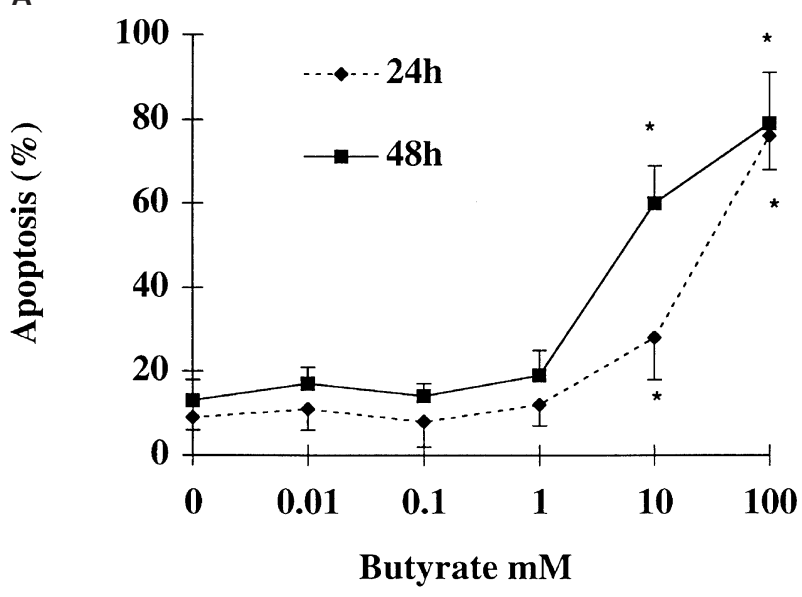

B

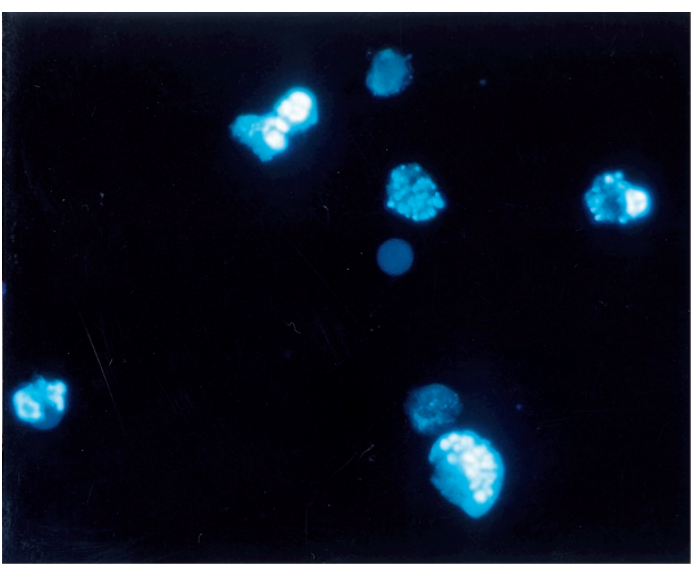

C

\section{CONTROL}

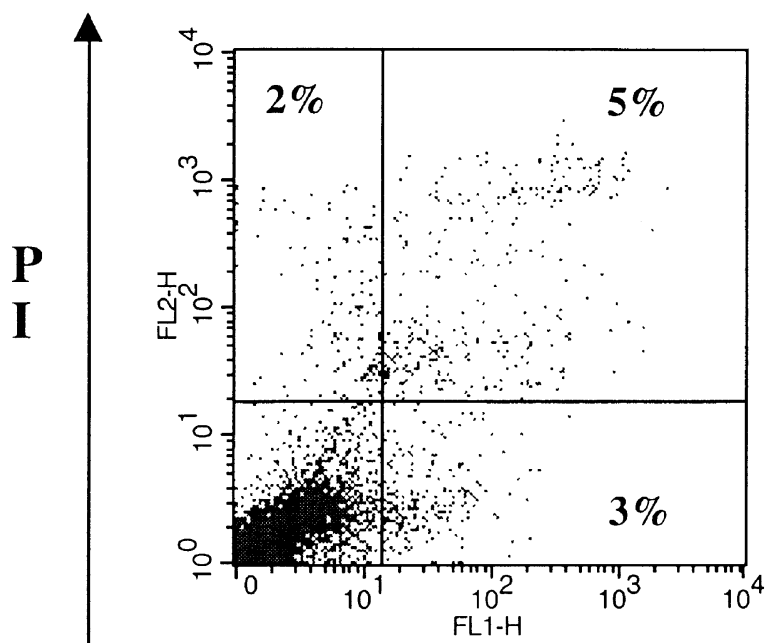

Figure 2 Effect of butyrate on Caco-2 cell apoptosis. (a) Stimulation with butyrate $0.01-100 \mathrm{mM}$ induced Caco-2 cell apoptosis in a dose-dependent manner as quantified by flow cytometry. ${ }^{*} P<0.01$. (b) Immunofluorescence microscopy after staining with the HOECHST 33342 DNA dye revealed the typical features of apoptotic cells, with nuclear shrinkage, condensation and fragmentation in butyrate-treated Caco-2 cells. The nuclei of untreated cells have uniformly regular, oval shape. Original magnification $\times 800$. (c) Detection of the expression of phosphatidyl serine on the outer leaflet of the plasma membrane on apoptotic Caco-2 cells. During early apoptosis, butyrate-treated Caco-2 cells expressed phosphatidyl serine which binds FITC-labeled Annexin V, allowing quantification by flow cytometry. One representative of five similar experiences is shown

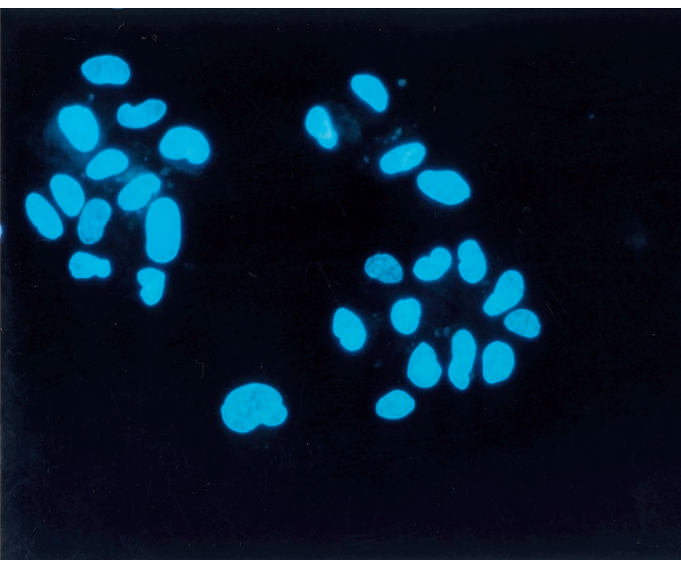

BUTYRATE $50 \mathrm{mM}$

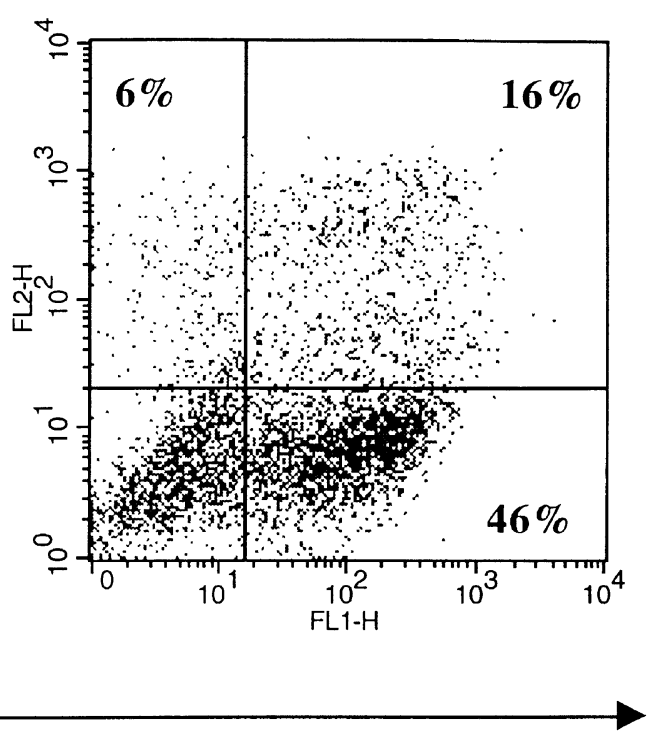

ANNEXIN-V-FITC 
A

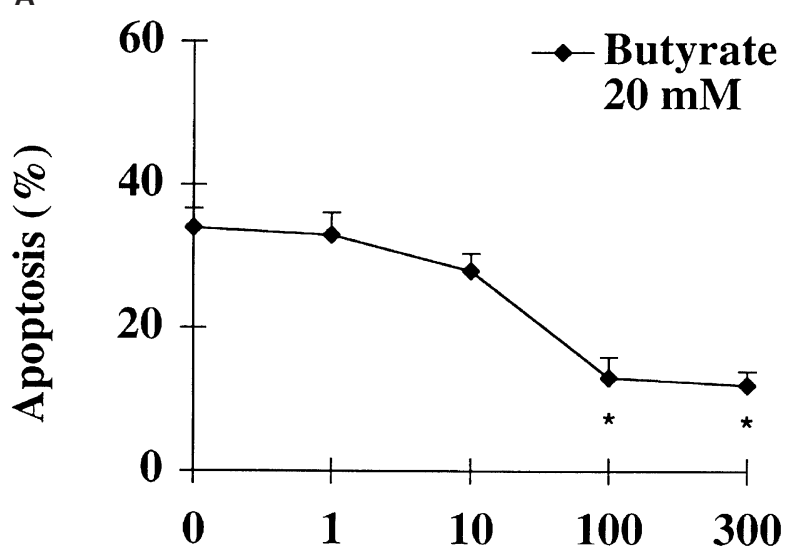

Cycloheximide $(\mu \mathrm{g} / \mathrm{ml})$

B

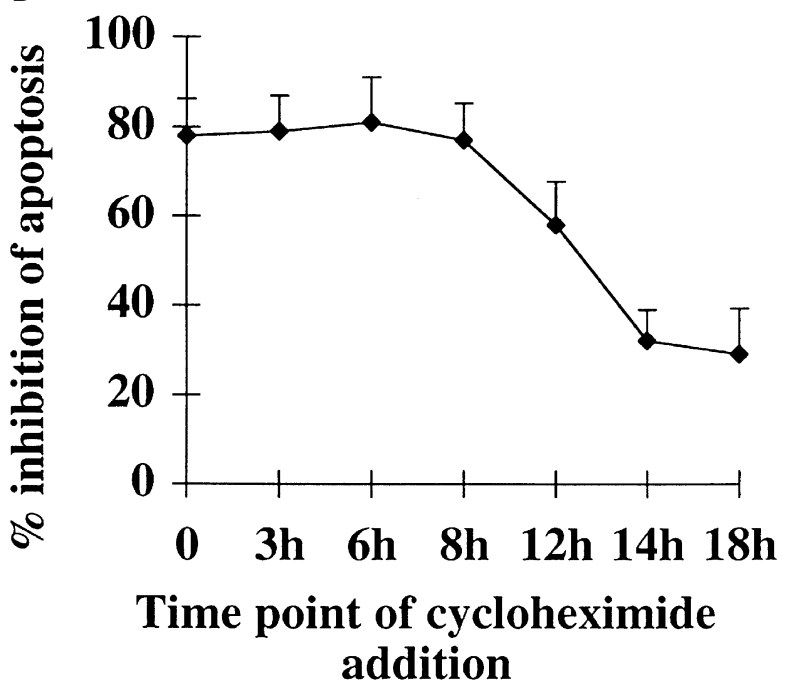

Figure 3 Effect of protein synthesis inhibition on butyrate-induced Caco-2 cell apoptosis. (a) Simultaneous stimulation of Caco-cells with butyrate $(20 \mathrm{mM})$ and the protein synthesis inhibitor cycloheximide $(1-100 \mu \mathrm{g} / \mathrm{ml})$, resulted in a clear suppression of butyrate induced apoptosis. (b) Time course analysis after the addition of cycloheximide to butyrate-stimulated Caco-2 cells revealed that complete inhibition was observed within $8 \mathrm{~h}$, with progressively less protective effect thereafter. No significant protection was seen when cycloheximide was added $14 \mathrm{~h}$ or later after butyrate-stimulation ${ }^{*} P<0.01$

upregulated by butyrate, in a dose-dependent manner (Figure $6 a)$. Increased expression of bak in response to butyrate (50 $\mathrm{mM}$ ) was detectable after $12-16 \mathrm{~h}$ of butyrate treatment and progressively increased thereafter. Once again, in the presence of cycloheximide $(100-\mu \mathrm{g} / \mathrm{ml})$, butyrate induced bak-upregulation was completely blocked (Figure 6b). Caco-2 cell expression of the anti-apoptotic protein bcl-2 was not changed by butyrate, under all experimental conditions tested. Taken together, the data show that butyrate induced a strong shift in the ration of anti- to pro-apoptotic bcl-family proteins, in favor of an apoptotic response.

\section{A Butyrate}

$\begin{array}{lllllll}0 & 0.1 & 1 & 5 & 10 & 20 & 100\end{array}$

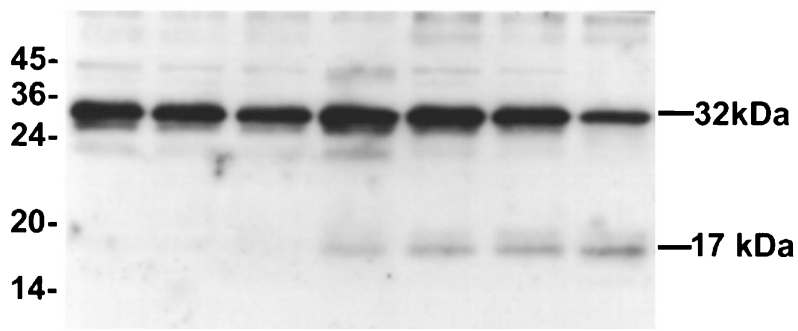

\section{B Butyrate+Cycloheximide \\ $\begin{array}{lllllll}0 & 0.1 & 1 & 5 & 10 & 20 & 100\end{array}$}

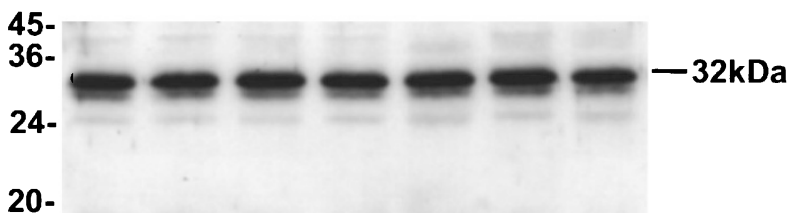

20-

14-

$-17 \mathrm{kDa}$

C

\section{Butyrate}

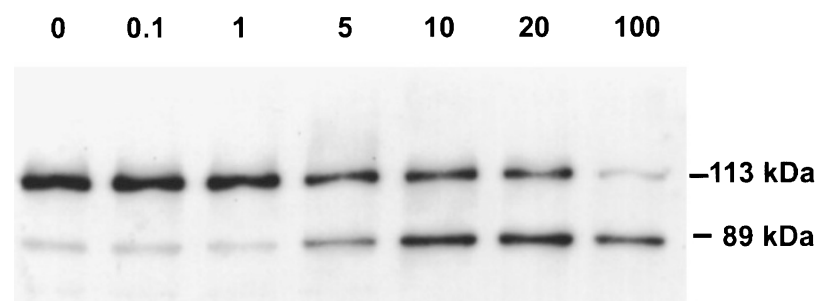

Figure 4 Western blot analysis of the effect of butyrate on the caspasecascade. Immunoblotting was performed as described in Material and Methods. (a) Butyrate $(0.1-100 \mathrm{mM}, 24 \mathrm{~h})$ induced the cleavage of caspase$3(32 \mathrm{kDa})$ into its active form $(17 \mathrm{kDa})$. (b) The activation of caspase- 3 by butyrate $(0.1-100 \mathrm{mM})$ was completely inhibited in the presence of the protein synthesis inhibitor cycloheximide $(100 \mu \mathrm{g} / \mathrm{ml})$. (c) The caspase-2 mediated degradation of PARP $(113 \mathrm{kDa})$ into a $89 \mathrm{kDa}$ fragment was clearly butyrate dose-dependent

\section{Discussion}

This study provides new insight into the molecular mechanisms by which butyrate induces colon cancer cell apoptosis. Using the Caco-2 cell model, the date presented demonstrate that butyrate directly activates the intracellular caspase cascade. This classical apoptosis pathway transduces the apoptotic signal of a great variety of stimuli, including TNF $\alpha$, Fas ligand, and others. ${ }^{14,15}$ One endpoint of this cascade is the activation of caspase-3, which rapidly cleaves several key substrates implicated in the execution of apoptotic cell death, including PARP, DFF-45, lamin A, etc. ${ }^{15}$ The inactivation of PARP leads to a breakdown of the DNA-repair system, allowing its degradation. ${ }^{16}$ The importance of this step in butyrate-induced apoptosis was further underscored in the 


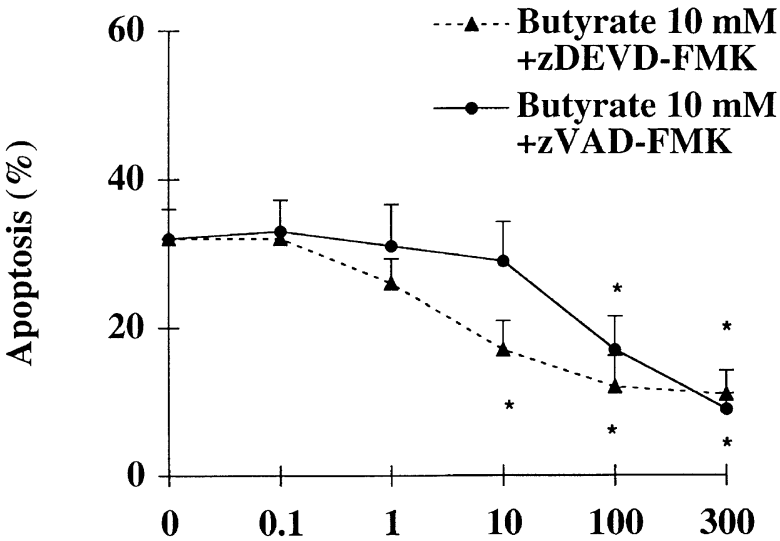

Inhibitor concentration $(\mu \mathrm{M})$

Figure 5 Inhibition of butyrate-induced Caco-2 cell apoptosis by zDEVDFMK. Butyrate-induced Caco-2 cell apoptosis was quantified by flow cytometry using the Apo-Alert-Annexin V assay. The addition of zDEVD-FMK (0.1$300 \mu \mathrm{M})$, a caspase-3 inhibitor, potently blocked butyrate-induced apoptosis, in a dose-dependent manner. Similarly, the ICE-inhibitor ZVAD-FMK, a broadrange caspase inhibitor, blocked butyrate induced Caco-2 cell apoptosis in a dose-dependent manner, without shifting the apoptotic response to a necrotic form of cell death. ${ }^{*} P<0.01$

A

\section{Butyrate}

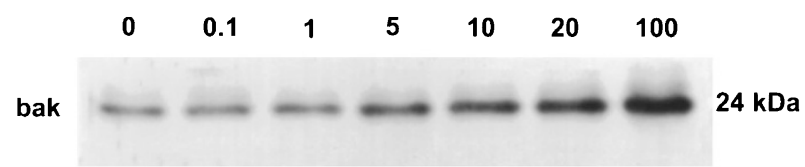

bcl-2

$26 \mathrm{kDa}$

B

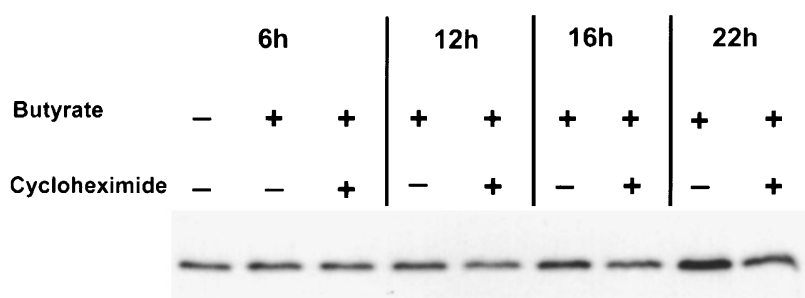

Figure 6 Effect of butyrate on Caco-2 cell bcl-2/bak protein expression. (a) Western blot analysis revealed that butyrate did not change Caco-cell bcl-2 expression, whereas bak was strongly induced by butyrate $(0.1-100 \mathrm{mM}$, $24 \mathrm{~h})$. (b) Time-course analysis revealed an increased bak expression after $12-16 \mathrm{~h}$ in response to butyrate $(50 \mathrm{mM})$. This upregulation was completely suppressed in the presence of cycloheximide $(100 \mu \mathrm{g} / \mathrm{ml})$

present study. Inactivation of caspase-3 with zDEVD-FMK, which irreversibly binds with a very high affinity to the catalytic site of this particular caspase, completely inhibited butyrateinduced Caco-2 cell apoptosis.
The use of the broad-range caspase-inhibitor zVADFMK, which blocks ICE-like caspases (caspase-1, -4, -5), at low concentrations and CPP-32-like caspases (caspase3) at higher concentrations, confirmed the necessity of the caspase-cascade in the execution of butyrate induced apoptosis. Recent reports indicated that complete caspase inhibition with this inhibitor may shift the apoptotic response to a necrotic form of cell death. This was demonstrated for the FAS ligand in murine L929 fibrosarcoma cells ${ }^{17}$ and for TNF $\alpha$ in intestinal epithelial cells. ${ }^{18}$ In contrast to these observations, no necrotic cell death was observed in Caco2 cells in response to butyrate, despite complete caspase inhibition with high zVAD-FMK doses. The data indicate that distinct signaling mechanisms exist for butyrate, clearly different from those employed by the death receptors FAS or the p55 TNF-R. Taken together, our results demonstrate that butyrate-induced Caco-2 cell apoptosis is caspase-3 dependent, in keeping with a recent report in other cell lines. ${ }^{13}$

Butyrate is known to affect the expression of several genes potentially involved into the regulation of cell death. ${ }^{19}$ It is well established that butyrate exerts many effects via the inhibition of histone deacetylase, which leads to chromatin relaxation, altering gene expression. ${ }^{20}$ Our data led us to speculate that one of these newly transcripted gene products is responsible for the activation of the caspase cascade. The most likely candidate in the Caco-2 cell model might be one member of the bcl-2 gene family. These proteins are important regulators and modulators of apoptotic signaling, primarily acting at the mitochondrial level. ${ }^{21} \mathrm{Bcl}-2$ and $\mathrm{bcl}-\mathrm{xl}$ are potent inhibitors of the caspase-cascade, whereas other proteins of this family, such as bax or bak, possess potent pro-apoptotic activity. ${ }^{22}$ Clem et al ${ }^{23}$ recently showed that bcl-xl directly interacts with specific caspases. Upon the induction of apoptosis, this protein is cleaved by caspases- 1 and -3 , thereby allowing further propagation of the initial apoptotic signal. Our data indicate that the butyrate-induced pathway is closely involved with the mitochondrial bcl-pathway, known to be critical to apoptosis in other models. ${ }^{24,25}$ In this study, butyrate markedly upregulated the expression of pro-apoptotic bak, without altering Caco-2 cell bcl-2 expression. Time-course analysis of this upregulation revealed that the increased bak-expression was detectable just prior or concomitant to the occurrence of Caco-2 cell apoptosis, after $12-16 \mathrm{~h}$ of butyrate stimulation. Previous reports ${ }^{26}$ clearly delineated that bak expression correlated positively with apoptosis in the normal intestinal epithelium. Furthermore, colon cancer cells, significantly more resistant to apoptosis than non-transformed colonocytes, display reduced levels of bak, whereas the expression of other pro-apoptotic bcl-2 family members, such as bax, is unaltered. ${ }^{27,28}$ The ratio of pro- to antiapoptotic bcl-2 proteins is an important regulator of a cell's susceptibility to undergo apoptosis upon a specific proapoptotic stimulus. Therefore, our observation of an increased bak expression in butyrate-stimulated Caco-2 cells points out to an additional, important effect of this particular short chain fatty acid by which it can enhance a colon cancer cell's susceptibility to apoptotic stimuli. 
The relatively long lag-interval (14-16 h) between butyrate-stimulation and the induction of apoptosis is very suggestive of additional intermediate steps requiring protein synthesis. Indeed, inhibition of protein-synthesis with cycloheximide completely abolished butyrate induced Caco-2 cell apoptosis, in keeping with reports in other cells. ${ }^{13}$ Furthermore, no butyrate induced activation of caspase-3 was observed in the presence of cycloheximide, suggesting that protein synthesis was required upstream of the caspase-cascade. To test the hypothesis that butyrate-induced bak upregulation as a critical step requires protein synthesis, the expression of this proapoptotic bcl-2 family member was analyzed at various time points in the presence or absence of cycloheximide. No butyrate induced upregulation of bak was observed when protein synthesis was completely blocked by cycloheximide, even after prolonged stimulation (36 h). Inhibition of protein synthesis at various time intervals after the onset of stimulation with butyrate revealed that cycloheximide completely suppressed butyrate-induced apoptosis when added during the first $8 \mathrm{~h}$ of butyrate stimulation, with progressively less effect when added later on. Addition of cycloheximide after $14 \mathrm{~h}$ of butyratestimulation, a time point where bak is already upregulated, failed to reduce Caco-2 cell apoptosis rate, indicating that inhibition of bak expression might play at important role in butyrate-induced Caco-2 cell apoptosis. However, we cannot completely exclude the possibility that additional events, upstream of bak, which also require protein synthesis, are implicated.

The major sources of intestinal butyrate are dietary, as an important endproduct of the colonic bacterial fermentation of fiber or milk fat. Butyrate concentrations effective in inducing cancer cell apoptosis are easily achieved under physiological conditions in the colon. Normal, nontransformed colonocytes use these short chain fatty acids as a major energy source. However, as clearly demonstrated in this and other studies, colon cancer cells are rapidly induced to undergo apoptosis when incubated with butyrate. ${ }^{1,4}$ In summary, in this report we have uncovered two major pathways which mediate the apoptotic response to butyrate in colon cancer cells: the caspase-cascade and via upregulation of the pro-apoptotic protein bak at the mitochondrial level. Additional studies are needed to further elucidate the mechanisms upstream of caspase-3.

\section{Material and Methods}

\section{Cell culture and materials}

Caco-2 cells between passages 30-45 (American Type Culture Collection, Rockville, MD, USA), were cultured at $37^{\circ} \mathrm{C}$ with $5 \% \mathrm{CO}_{2}$ in Minimal Essential Medium (MEM, Gibco BRL, Grand Island, NY, USA), containing $1 \%$ penicillin/streptomycin, 1\% MEM non-essential amino acids (Gibco BRL) and 5\% fetal calf serum (FCS, Gibco BRL). The agents used in this study were: Na-butyrate (Sigma, St. Louis, MO, USA), the protein inhibitor cycloheximide (Sigma), the caspase-3 substrate and inhibitor zDEVD-FMK (Kamiya, Thousand Oaks, CA, USA), the ICE-inhibitor zVAD-FMK (Kamiya), anti-caspase-3 antibody
(Pharmingen, Mississauga, Ont., Canada) which recognizes the native (32 kDA) and the proteolytically active form (17 kDa), anti-PARPantibody (Strategene), anti-mouse-horseradish peroxidase (Promega, Madison, WI, USA anti-bcl-2-FITC (DAKO, Mississauga, Ont., Canada), anti-bcl-2 antibody (Oncogene, Cambridge, MA, USA), anti-bak-antibody (Pharmigen), propidium iodide (PI, Sigma), and HOECHST 33342-DNA stain (Boehringer, Mannheim, Germany).

\section{Proliferation assay}

These experiments were performed in 24-multi-well plates (Falcon Plastics, Oxnard, CA, USA) at a density of $5 \times 10^{4}$ cells $/ \mathrm{ml}$. After a $24 \mathrm{~h}$ stabilization period in FCS-free medium, Caco-2 cells were cultured in the absence (control) or presence of butyrate $(0.01-10 \mathrm{mM})$. Proliferation was quantified by monitoring changes in DNA synthesis, as measured by $\left[{ }^{3} \mathrm{H}\right]$ thymidine uptake $(2 \mu \mathrm{Ci} / \mathrm{ml})$ added during the last $2 \mathrm{~h}$ of culture, as previously described. ${ }^{29}$ Results were expressed as percentage of $\left[{ }^{3} \mathrm{H}\right]$ incorporation relative to control wells without butyrate.

\section{Apoptosis assays}

Caco-2 cells were cultured in 24-multi-well plates to subconfluency and stimulated with butyrate $(0.1-100 \mathrm{mM})$ and/or zDEVD-FMK $(0.1-$ $200 \mu \mathrm{M})$, or zVAD-FMK $(1-300 \mu \mathrm{M})$ for up to $72 \mathrm{~h}$. In parallel, experiments were performed in the presence of cycloheximide $(100 \mu \mathrm{g} / \mathrm{ml})$ added simultaneously or after various time intervals (3$24 \mathrm{~h}$ ) after butyrate-stimulation. Apoptotic cells were identified using the Apo-Alert Annexin V kit (Clontech, Palo Alto, CA, USA), according to the manufacturer's instructions. This allows the detection of phosphatidyl-serine on the external cell membrane early in apoptotic cell death. Increased permeability for the DNA-dye PI is noted during late phase apoptosis. Butyrate-induced apoptosis was thereafter quantified by flow cytometry (FACScan, Becton Dickinson, Mississauga, Ont., Canada). In parallel, the typical morphological criteria of apoptosis were confirmed by immunofluorescence after staining with the DNA-dye HOECHST $33342(1 \mu \mathrm{g} / \mathrm{ml})$.

\section{Immunoblotting}

The activation of caspase- 3 and subsequent degradation of poly(ADP-ribose) polymerase (PARP) were determined by Western blotting. In addition, changes in the expression of bcl-2 or bak were monitored by immunoblotting. Butyrate $(0.1-100 \mathrm{mM})$ or butyrate+cycloheximide $(100 \mathrm{mg} / \mathrm{ml})$-treated and control Caco-2 cell lysates were prepared using an ice-cold lysis buffer $(50 \mathrm{mM}$ Tris, $150 \mathrm{mM} \mathrm{NaCl}, 10 \mathrm{mM}$ EDTA, $1 \%$ Triton) and a mixture of protease inhibitors (Boehringer). After determination of protein concentrations, equivalent samples were resolved on $8-14 \%$ SDS-polyacrylamide gels and transferred to nitrocellulose membranes (Bio-Rad). For immunodetection, the membranes were incubated overnight with anticaspase-3- $(1: 1000)$, anti-PARP- $(1: 3000)$, anti-bcl-2 $(1: 100)$ or antibak-antibody $(1: 800)$ in Tris-buffered saline/Tween-20-1\% milk powder, followed by incubation with the corresponding alkaline phosphatase-conjugated antibody (anti-mouse-lgG 1:2000, antirabbit-lgG 1:2500). The bands were read by enhanced chemiluminescence (ECL-kit, Amersham).

\section{Experimental design and statistical analysis}

All experiments were performed in duplicate and were repeated at least four times. Representative experiments or mean values \pm S.D. 
are shown. Statistical significance was determined by the MannWhitney U-test. Differences with $P$ values $<0.05$ were considered significant.

\section{Acknowledgements}

This study was supported by a research grant from the Dairy Farmers of Canada (E.G. Seidman, I. Qureshi, D.S.R. Sarma), by a Research Fellowship Award from the Deutsche Forschungesemeinschaft (RU 694, 1-1, F.M. Ruemmele), and Research Scholarship Awards from the Fonds de la Recherche en Sante de Quebec (E.G. Seidman, E. Levy).

\section{References}

1. Hague A, Manning AM, Hanlon KA, Huschtscha LL, Hart D and Paraskeva C (1993) Sodium butyrate induces apoptosis in human colonic tumor cell lines in a p53-independent pathway: implication for the possible role of dietary fibers in the prevention of large bowel cancer. Int. J. Cancer. 55: 498-505.

2. Giardina C and Inan MS (1998) Nonsteroidal anti-inflammatory drugs, short chain fatty acids and reactive metabolism in human colorectal cancer cells. Biochim. Biophys. Acta. 1401: 277-288.

3. Velazquez OC, Lederer HM and Rombeau JL (1996) Butyrate and the colonocyte-implications for neoplasia. Dig. Dis. Sci. 41: 727-739.

4. Mclntyre A, Gibson PR and Young GP (1993) Butyrate production from dietary fibers and protection against large bowel cancer in rat model. Gut. 34: 386-391.

5. Toscani A, Soprano DR and Soprano KJ (1988) Molecular analysis of sodium butyrate-induced growth arrest. Oncogene Res. 3: 233-238.

6. Kim YS, Tsao D, Siddiqui B, Whitehead JS, Arnstein P, Bennett J and Hicks J (1980) Effects of sodium butyrate and dimethylsulfoxide on biochemical properties of human colon cancer cells. Cancer. 45: 1185-1192.

7. Whitehead RH, Young GP and Bhathal PS (1996) Effects of short chain fatty acids on a new human colon carcinoma cell line (LIM1215). Gut. 27: 1457-1466.

8. Medina V, Afonso JJ, Alvarez-Arguelles H, Hernandez C and Gonzalez F (1998) Sodium butyrate inhibits carncinoma development in a 1,2-dimethylhydrazineinduced rat colon cancer. JPEN. 22: 14-17.

9. Calabresse $C$, Venturini L, Ronco G, Villa $P$, Chomienne $C$ and Belpomme D (1993) Butyric acid and its monosaccharide ester induce apoptosis in the HL-60 cell. Biochem. Biophys. Res. Comm. 195: 31-38.

10. Dolara P, Caderni G, Luceri $C$ and Tessifore $L$ (1998) Slow release pellets of sodium butyrate increase apoptosis in the colon of rats treated with azoxymethane. Proc. Amer. Assoc. Cancer Res. 39: 197.

11. El-Mahdani N, Vaillant JC, Guigeut M, Prevost S, Bertrand V, Bernard C, Parc R and Hermelin B (1997) Overexpression of p53 mRNA in colorectal cancer and its relationship to $\mathrm{p} 53$ gene mutation. Br. J. Cancer. 75: 528-536.

12. Alnemri ES. Livingston DJ, Nicholson DW, Salvesen G, Thornberry NA, Wong WW and Yuan J (1997) Human ICD/CED-3 protease nomenclature. Cell. 87: 171.
13. Medina V, Edmonds B, Young GP, James R, Appleton S and Zalewski PD (1997) Induction of caspase-3 protease activity and apoptosis by butyrate and trichostatin A (inhibitors of histone deacetylase): dependence on protein synthesis and synergy with a mitochondrial/cytochrome c-dependent pathway. Cancer Res. 57: 3697-3707.

14. Nagata S and Goldstein P (1995) The Fas death factor. Science. 267: 1449 1456.

15. Nagata S (1997) Apoptosis by death factor. Cell. 88: 355-365.

16. Patel T, Gores GJ and Kaufmann SH (1996) The role of proteases during apoptosis. FASEB J. 10: 587-597.

17. Vercammen D, Brouckaert G, Denecker G, Van de Craen M, Declercq W, Fiers W and Vandenabeele $P$ (1998) Dual signaling of the Fas receptor: initiation of both apoptotic and necrotic cell death pathways. J. Exp Med. 188: 919-930.

18. Ruemmele FM, Russo P, Beaulieu J-F, Dionne S, Levy E, Lentze MJ and Seidman EG (1999) Susceptibility to FAS-induced apoptosis in human nontumoral enterocytes: Role of costimulatory factors. J. Cell Physiol. 180: (in press).

19. Young GP and Gibson PR (1995) Butyrate and the human cancer cell. In: Physiologic and Clinical Aspects of Short-Chain Fatty Acids. JJ Cummings, JL Rombeau, T Sakata (eds). Cambridge, Cambridge University Press. 319-336.

20. Boffa LC, Vidali G, Mann RS and Allfrey VG (1978) Suppression of histone deacetylation in vivo and in vitro by sodium butyrate. J. Biol. Chem. 25: $3364-$ 3366.

21. Nunez G and Clark MF (1994) The bcl-2 family of proteins: regulators of cell death and survival. Trends Cell Biol. 4: 399-403.

22. Miyashita Rand Reed JC (1995) Tumor suppressorp53 is a direct transcriptional activator of the human bax gene. Cell. 80: 293-299.

23. Chem RJ, Cheng EHY, Karp CL, Kirsch DG, Ueno K, Takahashi A, Kastan MB, Griffin DE, Earnshaw WC, Veliuona MA and Hardwick JM (1998) Modulation of cell death by bcl-xl through caspase interaction. Proc. Natl. Acad. Sci. USA 95: $554-559$.

24. Ito N, Tsujimoto $Y$ and Nagata S (1993) Effect of bcl-2 on Fas antigen-mediated cell death. J. Immunol. 151: $621-627$.

25. Oltavi Z, Milliman CL and Korsmeyer SJ (1993) Bcl-2 heterodimerizes in vivo with a conserved homologue, bax, that accelerates programmed cell death. Cell. 57: $609-619$.

26. Moss SF, Agarwal B, Arber N, Guan RJ, Krajewski M, Krajewski S, Reed JC and Holt PR (1996) Increased intestinal bak expression results in apoptosis. Biochem. Biophys. Res. Commun. 223: 199-203.

27. Krajewski S, Krajewski M and Reed JC (1996) Immunohistochemical analysis of in vivo pattern of bak expression, a proapoptotic member of the bcl-2 protein family. Cancer Res. 56: 2849-2855

28. Krajewska M, Moss SF, Krajewski S, Song K, Holt PR and Reed JC (1996) Elevated expression of $\mathrm{bcl}-\mathrm{x}$ and reduced bak in primary colorectal adenocarcinomas. Cancer Res. 56: 2422-2427.

29. Ruemmele FM, Gurbindo C, Mansour AM, Marchand R, Levy E and Seidman EG (1998) Effect of interferon gamma on growth, apoptosis and class II antigen expression of immature intestinal crypt (IEC-6). J. Cell Physiol. 176: 120-126. 